\title{
COST-EFFECTIVENESS SIMULATION ANALYSIS OF INTERNET-BASED INSURANCE PRESCRIPTION VERIFICATION SYSTEM
}

\author{
Samira Rasouli ${ }^{1}$, Majid Rahimi ${ }^{2}$, Saeid Eslami ${ }^{* 3,4}$
}

1: M.Sc. student in Medical Informatics, Student Research Committee, Department of Medical Informatics, Faculty of Medicine, Mashhad University of Medical Sciences, Mashhad, Iran

2: Pharm.D., The Iranian Social Security Organization, Mashhad, Iran

3: Pharm.D., Pharmaceutical Research Center, School of Pharmacy, Mashhad University of Medical Sciences, Mashhad, Iran

4: Ph.D. in Medical Informatics, Department of Medical Informatics, Faculty of Medicine, Mashhad University of Medical Sciences, Mashhad, Iran

Correspondence:

Tel: +98.09154403990, E-mail: EslamiS@mums.ac.ir

\section{TYPE OF ARTICLE: CONFERENCE ABSTRACT}

\begin{abstract}
Introduction: One common cited reason for investigating Internet-based systems is the capabilities of Internet interventions to reduce health services and delivery costs. The purpose of this study was to estimate the economic impact of implementing Internet-based insurance prescription verification system on a patient's transportation cost.

Methods: We performed a cost-effectiveness study to analyze the financial effects of an Internet-based insurance prescription verification system. All verified prescriptions of April 20, 2015 to May 20, 2015 were extracted from the Iranian Social Security Organization database. For all pharmacies, travel distances were computed with the aid of Google Map. Then, all the measurable transportation costs, including public or private travel cost, transit's direct costs and revenues and transit's secondary impacts such as cost of air pollution and accidents were estimated per kilometer. The primary outcome measure was transportation cost with or without applying the Internet-based insurance prescription verification system for a one-month period.

Results: Over a one-month period, 15,554 prescriptions were registered in the Internet-based insurance prescription verification system by 150 pharmacies. For all these pharmacies, total travel distances to the Iranian Social Security Organization was 57,398.71 kilometers. The total cost of public transportation and private transportation in Mashhad was computed \$3.5861 and \$3.7721 per kilometer, respectively. Because the share of public transportation in Mashhad is $45 \%$, the estimated benefit of using an Internet-based insurance prescription verification system for a one-month period was $\$ 211,709.5$.

Conclusion: Implementation of an Internet-based insurance prescription verification system can result
\end{abstract} in a positive financial return on investment to the health care organizations.

KEYWORDS: Cost-Effectiveness, Insurance, Transportation, Prescription verification system, Internet-Based

\footnotetext{
Abstracts of First National Congress of Medical Informatics, Mashhad, Iran, February 2017

(C) 2017 The Authors. This is an open access article under the terms of the Creative Commons Attribution-NonCommercialNoDerivs License, which permits use and distribution in any medium, provided the original work is properly cited, the use is non-commercial and no modifications or adaptations are made. 